Original Article

\title{
ANTI-OBESITY EFFECTS OF THE METHANOL EXTRACT OF MOMORDICA FOETIDA (CUCURBITACEAE) IN MALE WISTAR RATS
}

\author{
CHOUMESSI T. APHRODITE ${ }^{1 *}$, CHI H. A. NKWENTI ${ }^{1}$, SOH DESIRE ${ }^{2}$, MBOUH MARIAM ${ }^{1}$, ATSAMO A. DONATIEN ${ }^{3}$
}

${ }^{1}$ Department of Biochemistry, Faculty of Science, the University of Bamenda, PO Box 39, Bambili, Cameroon, ${ }^{2}$ Department of Chemistry, Higher Teacher Training College, the University of Bamenda, PO Box 39 Bambili, Cameroon, ${ }^{3}$ Department of Animal Biology and Physiology, Faculty of Science, University of Yaounde 1, POBox 812, Yaounde, Cameroon *Email: achoumessi@yahoo.fr

Received: 24 Feb 2021, Revised and Accepted: 28 Apr 2021

\begin{abstract}
Objective: This study was designed to evaluate the effect of the methanol extract of M. foetida (MEMf) on high fat diet-induced obese male rats.

Methods: Four groups (experimental groups) of 6 male Wistar rats each were fed with a high-fat diet (HFD) for $4 \mathrm{w}$ and then treated with either distilled water (control group), MEMf (50 or $100 \mathrm{mg} / \mathrm{kg}$ ) or the reference compound Atorvastatin $(10 \mathrm{mg} / \mathrm{kg}$ ) for 27 days. The body weight was recorded every two days. A fifth group made up of rats (normal diet group) not subjected to a HFD was used as a negative control for the HFD obese rats. The Lee index, lipid profile and antioxidant parameters were assessed using animal body weight and biochemical methods, respectively.

Results: HFD induced an increase $(\mathrm{P}<0.05)$ in the body and liver weights and the relative abdominal fat pad of the animals in the experimental groups as compared to those in the normal diet group. Also, HFD in the experimental groups reduced $(\mathrm{P}<0.05)$ superoxide dismutase and catalase activities, glutathione levels and increased lipid peroxidation in the liver, heart and kidney as well as altered lipid profile (increased serum triglycerides, total cholesterol, low-density lipoproteins (LDL-C), very low-density lipoproteins (VLDL-C), decreased high-density lipoproteins (HDL-C), increased atherogenic index and coronary risk index), when compared to the normal diet animals. All altered parameters were
\end{abstract} subsequently normalized when obese rats received either MEMf (50 or $100 \mathrm{mg} / \mathrm{kg}$ ) or the reference drug Atorvastatin.

Conclusion: This study demonstrates the potential of MEMf to normalize hyperlipidemia, oxidative stress and animal visceral organ weights increased by HFD in rats. Thus, M. foetida is an interesting medicinal plant that could be exploited as sources of anti-obesity agents.

Keywords: High fat diet, Lipid profile, Momordica foetida, Male rats, Obesity, Oxidative stress

(C) 2021 The Authors. Published by Innovare Academic Sciences Pvt Ltd. This is an open access article under the CC BY license (https://creativecommons.org/licenses/by/4.0/) DOI: https://dx.doi.org/10.22159/ijpps.2021v13i6.41207. Journal homepage: https://innovareacademics.in/journals/index.php/ijpps.

\section{INTRODUCTION}

Obesity is a condition in which body fat accumulates to the extent of causing an adverse effect on health, leading to increased health problems and even reduced life expectations. The prevalence of obesity is increasing globally, with 1.9 billion adults overweight in 2016, and 650 million obese [1]. This prevalence varies between countries with the lowest being Japan (3.7\%) and the highest being the United States with $38.2 \%$ [2]. Sub-Saharan Africa countries are also facing the increasing burden of overweight and obesity among their populations. For instance, from 1975 to 2014 the trends of obesity in sub-Saharan Africa have increased by more than $7 \%$ in both genders [3]. For Cameroon, in 2019, the prevalence of overweight was estimated at $26.0 \%$ and the overall prevalence of obesity was $15.1 \%$ [4]

Obesity results from complex interactions of genetic, behavioral and environmental factors correlating with lifestyles, economic and social status [5]. It can only occur when the energy value of food eaten exceeds energy expended. This is known as "a positive energy balance", a situation whereby excess intake of energy in the form of food will inevitably appear as deposits of fat [6]. Regarding food consumption, study has suggested the existence of a rural-urban trend towards an increase lipid content of the diet, particularly in developing countries such as Cameroon [7]. Obesity facilitates the development of other metabolic disorders such as diabetes, hypertension and cardiovascular diseases [5]. Obesity also induces dysregulation of endocrine secretion of adipocytokines or adipokines characterized by chronic low-grade inflammation with increase oxidative stress. The latter damages cellular structures leading to the development of obesity-related complications [8]. Different measures such as a change in diet, increased physical activity, use of anti-obesity drugs, dietary supplements, and even surgery are proposed for management of obesity $[9,10]$. However, some approved anti-obesity drugs have been withdrawn because of their side effects. Surgery is not only costly but can also lead to serious adverse outcomes $[11,12]$. It is therefore vital to look for new therapeutic options for better management of obesity.

Medicinal plants, thanks to their phytonutrients and their uses for millenaries may constitute good sources of anti-obesity drugs [13] Herbal remedies are gaining more interests across the globe due to their ready availability, low cost and the common belief that they are natural and safer as compared to synthetic drugs. However, adequate scientific evidences on medicinal plants are needed for their optimal and rational usage. Hence, more detailed herbal studies are needed on suitable animal models in the search for novel anti-obesity agents. Previous reports showed the anti-obesity activity of some medicinal plants [14]. M. foetida is a medicinal plant, widely distributed in tropical Africa and has been used in folk medicine to control diabetes and hypertension which are the common complications in obesity. This plant is also used for the treatment of malaria and stomachache $[15,16]$. $M$. foetida is rich in antioxidants molecules phenolics, flavonoids and vitamin $\mathrm{C}$, and has shown significant antioxidant activity [17]. Therefore, $M$. foetida could display beneficial effects in the management of obesity and its related complications. This study therefore aimed at investigating the effects of the methanol extract of $M$. foetida in high fat inducedobese male Wistar rats.

\section{MATERIALS AND METHODS}

Collection of $M$. foetida and preparation of the methanol extract

The whole $M$. foetida plant (roots, stem and leaves) was harvested in Bambili village (Mezam division, Cameroon) in July 2018 and identified by a botanist of the Faculty of Science of the University of 
Bamenda. A specimen was preserved at the Cameroonian National Herbarium (HNC) under the voucher number 33420 HNC.

The plant was cleaned, dried at room temperature, chopped and finely ground. Four hundred grams of the dry matter from the whole plant were macerated into $2 \mathrm{~L}$ of methanol and allowed for $48 \mathrm{~h}$ with the mixture being swirled every $4 \mathrm{~h}$. The supernatant was collected and filtered using whatman $\mathrm{N}^{\circ} 1$ filter paper. The solvent was evaporated using a rotary evaporator under reduced pressure at 65 ${ }^{\circ} \mathrm{C}$ [17] and $9.57 \mathrm{~g}$ of the methanol extract of $M$. foetida (MEMf) obtained.

\section{Experimental animals}

Adult albino male Wistar rats were obtained from the animal house of the Department of Biochemistry (Faculty of Science, University of Bamenda, Cameroon). They were raised under standard conditions of temperature, humidity and a natural light/dark cycle. They had free access to food and drinking water during the experimental period. The animals were handled according to ethical guidelines of the Cameroon National Veterinary Laboratory as reference by the approval and health control No 001/17 CCS/MINEPIA/RD-NW/DD-ME/SSV.

\section{Reagents and kits}

Atorvastatin calcium tablets were purchased from Ajanta pharma limited, Kandivli (Mumbai, India). Total cholesterol, triglycerides and high density lipoprotein cholesterol (HDL-C) kits were purchased from Chronolab Systems (Barcelona, Spain). Trichloroacetic acid (TCA) and thiobarbituric acid (TBA) were obtained from Sigma Aldrich (France), while 2,2-dithio-5,50dibenzoic acid was gotten from Burgoynes and Co. (Mumbai, India). Other chemicals were of analytical grade.

\section{Experimental design}

Aside the normal diet control group (fed on a normal diet composed of $70 \%$ corn flour, $10 \%$ palm oil, $10 \%$ soya beans flour, $8 \%$ fish powder, $1 \%$ bone powder and $1 \%$ vitamin), the other rats (experimental groups) were given high fat diet (composed of 50\% corn flour, $30 \%$ palm oil, $10 \%$ soya beans flour, $8 \%$ fish powder, $1 \%$ bone powder and $1 \%$ vitamin) daily for $28 \mathrm{~d}$. The obese status of the animals was confirmed with Lee's index $\geq 300[18,19]$. Obese rats were partitioned into four groups of six animals each, orally treated for $27 \mathrm{~d}$ with either distilled water $(10 \mathrm{ml} / \mathrm{kg}), 50$ or $100 \mathrm{mg} / \mathrm{kg}$ of MEMf, or $10 \mathrm{mg} / \mathrm{kg}$ of Atorvastatin (the reference compound). The choice of doses of MEMf and Atorvastatin was based on previous studies $[19,20]$. The group of normal diet control rats was left untreated, and body weights of all animals were recorded every two days.

At the end of the treatment, the animals were fasted overnight, then anesthetized using diazepam $(10 \mathrm{mg} / \mathrm{kg})$ and sacrificed. Capillary blood was collected and serum prepared for subsequent biochemical analyses. The organs liver, heart, kidney as well as abdominal fat pads were dissected out and weighed. Homogenates $(20 \% \mathrm{w} / \mathrm{v}$, in

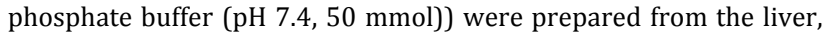
heart and kidney and used for the assessment of antioxidant parameters.

\section{Assessment of serum lipid profile}

Lipid profile was estimated in serum samples. To this end, parameters such as triglyceride (TG), total cholesterol (TC) and high-density lipoprotein (HDL-C) concentrations were quantified using Chrono Lab kits according to the manufacturer's instructions. Low-density lipoproteins (LD-CL), very low-density lipoproteins (VLDL-C), atherogenic index (AI) and coronary risk index (CRI) were estimated using the following formulae [21].

$$
\begin{gathered}
\text { VLDL-C }(\mathrm{mg} / \mathrm{dl})=\mathrm{TG} / 5 \\
\text { LDL-C }(\mathrm{mg} / \mathrm{dl})=\mathrm{TC}-(\text { HDL-C }+ \text { VLDL-C }) \\
\mathrm{AI}=\mathrm{LDL}-\mathrm{C} / \mathrm{HDL}-\mathrm{C} \\
\mathrm{CRI}=\mathrm{TC} / \text { HDL-C }
\end{gathered}
$$

\section{Evaluation of antioxidant parameters}

Superoxide Dismutase (SOD) and catalase activity were assayed according to the method of Misra and Fridovich [22]. Reduced glutathione was determined using Ellman reagent [23] Thiobarbituric acid reacting substances (TBARS) level was assessed by the method of Wilbur et al. [24]. All antioxidant parameters were corrected using protein levels in the respective organ homogenates, which were determined according to Gornall et al. [25].

\section{Statistical analysis}

The statistical package minitab version 18.1 was used for the analyses. Data were analyzed statistically using one-way analysis of variance (ANOVA), followed by Tukey's pair-wise comparison. Values were considered as statistically significant at $\mathrm{p}<0.05$.

\section{RESULTS}

\section{Effect of MEMf on the animal body weight and lee index}

Treatment with $50 \mathrm{mg} / \mathrm{kg}$ of MEMf or $10 \mathrm{mg} / \mathrm{kg}$ Atorvastatin reduced the body weight of HFD obese rats from day 15, as compared with the obese untreated group (fig. 1). However, the higher dose of the plant extract did not show any effect on the animal body weight.

As shown in table 1, all doses of the plant extract and the reference compound Atorvastatin significantly $(\mathrm{P}<0.05)$ reduced the Lee index as compared to the untreated HFD animals. However, none of the treatments totally normalize the Lee index with respect to the normal diet control group.

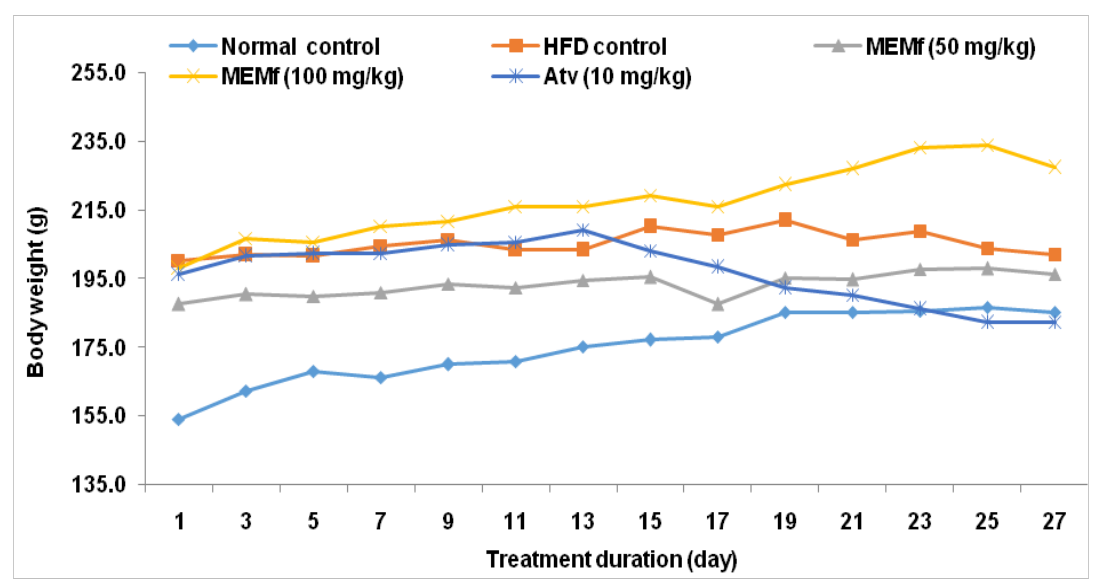

Fig. 1: Variation in the body weights of obese rats with different treatments, values represent mean \pm SD of 6 animals per group. Atvn: Atorvastatin, HFD: high-fat diet, MEMf: methanol extract of $M$. foetida 
Table 1: Lee index of animals during the experimentation

\begin{tabular}{lll}
\hline Groups & Lee index at beginning of the treatment & Lee index at day 27 \\
\hline Normal control & $275.95 \pm 2.55$ & $277.81 \pm 3.24^{\mathrm{a}}$ \\
HFD+DW $(10 \mathrm{ml} / \mathrm{kg})$ & $323.42 \pm 8.26$ & $331.61 \pm 7.11^{\mathrm{c}}$ \\
HFD+MEMf $(50 \mathrm{mg} / \mathrm{kg})$ & $319.47 \pm 2.10$ & $305.04 \pm 3.50^{\mathrm{b}}$ \\
HFD+MEMf $(100 \mathrm{mg} / \mathrm{kg})$ & $321.93 \pm 5.32$ & $310.42 \pm 4.85^{\mathrm{b}}$ \\
HFD+Atorvastatin $(10 \mathrm{mg} / \mathrm{kg})$ & $320.32 \pm 8.46$ & $302.82 \pm 4.68^{\mathrm{b}}$ \\
\hline
\end{tabular}

Values represent mean \pm SD of 6 animals per group. Values not sharing a common letter differ significantly with the normal control and with each other ( $\mathrm{P}<0.05$, Tukey's pair-wise comparison). DW: distilled water, HFD: high-fat diet, MEMf: methanol extract of $M$. foetida.

\section{Effect of MEMf on animal organ weights}

HFD significantly increased $(\mathrm{P}<0.05)$ the liver and fat pad weights of the obese control animals when compared to the normal control group (table 2). The MEMf or Atorvastatin significantly corrected the animal liver weight while only the reference molecule normalized the fat pad weight as compared to control normal rats. The other organs (kidney and heart) were affected neither by the HFD, plant extract, nor the reference compound Atorvastatin.

Table 2: Effect of MEMf on the relative fat pad, liver, heart and kidney weights

\begin{tabular}{|c|c|c|c|c|c|}
\hline Organ weight (g/100 g BW) & Normal control & Control HFD & MEMf (50 mg/kg) & MEMf (100 mg/kg) & $\operatorname{Atvn}(10 \mathrm{mg} / \mathrm{kg})$ \\
\hline Abdominal fat pad & $2.53 \pm 0.47^{b}$ & $3.51 \pm 0.54^{\mathrm{a}}$ & $2.82 \pm 0.46^{\mathrm{ab}}$ & $2.92 \pm 0.43^{\mathrm{ab}}$ & $2.41 \pm 0.30^{\mathrm{b}}$ \\
\hline Liver & $2.35 \pm 0.17^{b}$ & $3.09 \pm 0.30^{\mathrm{a}}$ & $2.60 \pm 0.14^{b}$ & $2.646 \pm 0.14^{b}$ & $2.38 \pm 0.13^{b}$ \\
\hline Kidney & $0.61 \pm 0.04^{a}$ & $0.63 \pm 0.07^{a}$ & $0.59 \pm 0.03^{a}$ & $0.62 \pm 0.06^{\mathrm{a}}$ & $0.55 \pm 0.04^{a}$ \\
\hline Heart & $0.37 \pm 0.03^{a}$ & $0.42 \pm 0.08^{a}$ & $0.39 \pm 0.03^{a}$ & $0.39 \pm 0.01^{\mathrm{a}}$ & $0.35 \pm 0.01^{\mathrm{a}}$ \\
\hline
\end{tabular}

Values represent mean \pm SD of 6 animals per group. Values not sharing a common letter differ significantly with the normal control and with each other ( $\mathrm{P}<0.05$, Tukey's pair-wise comparison). Atvn: Atorvastatin, HFD: high-fat diet, MEMf: methanol extract of $M$. foetida.

\section{Effect of MEMf on serum lipid profile}

Serum lipid profile of the rats after treatment with MEMf or Atorvastatin is shown in table 3. The HFD significantly $(\mathrm{P}<0.05)$ increased serum TC, TG, LDL-C and VLDL-C concentrations as well as
AI and CRI while it reduced $(\mathrm{P}<0.05)$ serum HDL-C levels. The treatment of rats with both doses of MEMf or the reference compound Atorvastatin normalized these parameters as compared with the normal control animals. The effect of the plant extract on animal lipid profile was comparable to that of the reference compound.

Table 3: Serum lipid profile of HFD-induced obese Wistar rats upon different treatments

\begin{tabular}{|c|c|c|c|c|c|}
\hline Lipid profile & Normal control & Control HFD & MEMf (50 mg/kg) & MEMf (100 mg/kg) & $\operatorname{Atvn}(10 \mathrm{mg} / \mathrm{kg})$ \\
\hline $\mathrm{TC}(\mathrm{mg} / \mathrm{dl})$ & $81.81 \pm 4.49 \mathrm{bc}$ & $125.82 \pm 2.77^{a}$ & $70.17 \pm 10.52^{c}$ & $90.21 \pm 10.53^{\mathrm{b}}$ & $86.48 \pm 7.82^{\mathrm{b}}$ \\
\hline $\mathrm{TG}(\mathrm{mg} / \mathrm{dl})$ & $66.33 \pm 8.62^{\mathrm{ab}}$ & $84.64 \pm 16.63^{a}$ & $50.27 \pm 9.10^{\mathrm{b}}$ & $76.48 \pm 12.42^{\mathrm{a}}$ & $73.21 \pm 2.99^{a}$ \\
\hline LDL-C (mg/dl) & $38.81 \pm 5.77^{b}$ & $85.59 \pm 7.20^{\mathrm{a}}$ & $40.64 \pm 5.03^{\mathrm{b}}$ & $52.66 \pm 7.80^{\mathrm{b}}$ & $45.97 \pm 7.15^{b}$ \\
\hline HDL-C (mg/dl) & $30.20 \pm 2.93^{\mathrm{a}}$ & $18.66 \pm 1.71^{\mathrm{d}}$ & $24.23 \pm 3.21^{\mathrm{bc}}$ & $22.01 \pm 2.00^{\mathrm{cd}}$ & $26.36 \pm 2.45^{\mathrm{b}}$ \\
\hline VLDL-C (mg/dl) & $12.90 \pm 2.48^{\mathrm{b}}$ & $21.34 \pm 4.07^{\mathrm{a}}$ & $11.38 \pm 0.61^{\mathrm{b}}$ & $15.29 \pm 2.48^{\mathrm{b}}$ & $14.64 \pm 0.59^{b}$ \\
\hline $\mathrm{AI}$ & $1.34 \pm 0.250^{\mathrm{c}}$ & $5.50 \pm 1.06^{\mathrm{a}}$ & $2.15 \pm 0.38^{\mathrm{bc}}$ & $2.65 \pm 0.43^{b}$ & $2.09 \pm 0.29 \mathrm{bc}$ \\
\hline CRI & $2.48 \pm 0.13^{\mathrm{b}}$ & $6.21 \pm 0.37 \mathrm{a}$ & $2.64 \pm 0.40^{\mathrm{b}}$ & $3.11 \pm 0.50^{\mathrm{b}}$ & $2.51 \pm 0.45^{b}$ \\
\hline
\end{tabular}

Values represent mean \pm SD of 6 animals per group. Values not sharing a common letter differ significantly with the normal control and with each other ( $\mathrm{P}<0.05$, Tukey's pair-wise comparison). AI: atherogenic index, Atvn: Atorvastatin, CRI: coronary risk index, HFD: high-fat diet, HDL-C: highdensity lipoproteins, LDL-C: low-density lipoproteins, MEMf: methanol extract of $M$. foetida, TC: total cholesterol, TG: triglyceride, VLDL-C: very-lowdensity lipoproteins.

Table 4: Antioxidant parameters of rat organs upon different treatments

\begin{tabular}{|c|c|c|c|c|c|c|}
\hline Organ & Antioxidant parameters & $\begin{array}{l}\text { Normal } \\
\text { control }\end{array}$ & Control HFD & MEMf (50 mg/kg) & $\begin{array}{l}\text { MEMf (100 } \\
\mathrm{mg} / \mathrm{kg})\end{array}$ & $\operatorname{Atvn}(10 \mathrm{mg} / \mathrm{kg})$ \\
\hline \multirow[t]{3}{*}{ Heart } & SOD (IU/mg of proteins) & $60.92 \pm 0.28^{a}$ & $15.54 \pm 0.59 \mathrm{e}$ & $44.76 \pm 4.70^{\mathrm{b}}$ & $30.94 \pm 4.50^{c}$ & $25.10 \pm 2.23^{\mathrm{d}}$ \\
\hline & CAT (IU/mg of proteins) & $66.39 \pm 9.04^{\mathrm{a}}$ & $50.38 \pm 8.32^{\mathrm{b}}$ & $60.99 \pm 7.08^{\mathrm{ab}}$ & $53.33 \pm 5.85^{b}$ & $54.18 \pm 7.24^{\mathrm{b}}$ \\
\hline & GSH (mmol/mg proteins) & $2.15 \pm 0.11^{\mathrm{a}}$ & $1.43 \pm 0.11^{\mathrm{c}}$ & $1.05 \pm 0.20^{\mathrm{bc}}$ & $1.92 \pm 0.37^{\mathrm{ab}}$ & $1.50 \pm 0.04^{c}$ \\
\hline \multirow[t]{4}{*}{ Liver } & SOD (IU/mg of proteins) & $33.13 \pm 1.88^{a}$ & $25.94 \pm 3.96^{b}$ & $31.69 \pm 1.93^{a}$ & $30.03 \pm 4.94^{\mathrm{ab}}$ & $29.45 \pm 4.28^{\mathrm{ab}}$ \\
\hline & CAT (IU/mg of proteins) & $111.91 \pm 22.23^{\mathrm{bc}}$ & $85.63 \pm 6.82^{c^{\prime}}$ & $152.48 \pm 22.50^{\mathrm{a}}$ & $101.73 \pm 2.89 \mathrm{bc}$ & $129.39 \pm 22.90^{\mathrm{ab}}$ \\
\hline & GSH (mmol/mg proteins) & $3.12 \pm 0.52^{\mathrm{a}}$ & $1.74 \pm 0.31^{c}$ & $2.02 \pm 0.37 \mathrm{bc}$ & $2.60 \pm 0.36^{\mathrm{ab}}$ & $2.30 \pm 0.40^{\mathrm{bc}}$ \\
\hline & TBARS (nmol/mg proteins) & $3.10 \pm 0.55^{b}$ & $7.17 \pm 1.36^{\mathrm{a}}$ & $4.35 \pm 0.77^{b}$ & $4.01 \pm 0.63^{\mathrm{b}}$ & $3.57 \pm 0.56^{b}$ \\
\hline \multirow[t]{4}{*}{ Kidney } & SOD (IU/mg of proteins) & $48.06 \pm 6.04^{\mathrm{a}}$ & $31.57 \pm 2.74^{c}$ & $40.92 \pm 5.38^{b}$ & $34.79 \pm 1.49 \mathrm{bc}$ & $36.36 \pm 4.98^{\mathrm{bc}}$ \\
\hline & CAT (IU/mg of proteins) & $85.66 \pm 9.27^{a}$ & $55.51 \pm 5.99^{c}$ & $70.54 \pm 8.22^{\mathrm{b}}$ & $54.26 \pm 8.10^{c}$ & $58.16 \pm 9.80^{c}$ \\
\hline & GSH (mmol/mg proteins) & $2.56 \pm 0.45^{\mathrm{ab}}$ & $2.15 \pm 0.31^{\mathrm{bc}}$ & $2.32 \pm 0.30^{\mathrm{ab}}$ & $2.79 \pm 0.35^{\mathrm{a}}$ & $1.75 \pm 0.16^{c}$ \\
\hline & TBARS (nmol/mg proteins) & $0.27 \pm 0.05^{c}$ & $0.50 \pm 0.02^{\mathrm{a}}$ & $0.40 \pm 0.07 \mathrm{~b}$ & $0.42 \pm 0.06^{\mathrm{ab}}$ & $0.29 \pm 0.05^{c}$ \\
\hline
\end{tabular}

Values represent mean \pm SD of 6 animals per group. Values not sharing a common letter differ significantly with the normal control and with eachother ( $\mathrm{P}<0.05$, Tukey's pair wise comparison). Atvn: Atorvastatin, CAT: catalase, GSH: glutathione, HFD: high-fat diet, MEMf: methanol extract of M. foetida, SOD: superoxide dismutase, TBARS: thiobarbituric acid reacting substances. 


\section{Effect of MEMf on antioxidant parameters}

In general, HFD significantly reduced $(\mathrm{P}<0.05)$ antioxidant enzyme activities and glutathione levels while it increased TBARS levels (table 4). The plant extract or Atorvastatin alleviated HFD effect on SOD activity. The lower dose of the plant extract $(50 \mathrm{mg} / \mathrm{kg})$ showed the most significant mitigating effect on this enzyme activity. The plant extract and the reference compound seemed to exhibit more significant antioxidant effect noted on liver than other organs. On catalase activity, the decreasing effect induced by the HFD in obese rats was normalized by MEMf, notably the dose $50 \mathrm{mg} / \mathrm{kg}$. Atorvastatin displayed a significant alleviating effect on the catalase activity only on liver homogenate. The lower dose of MEMf (50 $\mathrm{mg} / \mathrm{kg}$ ) and Atorvastatin also induced restoration of the glutathione levels depleted, and corrected increased TBARS levels.

\section{DISCUSSION}

Exposure of rats to HFD increased their body weights; a factor known as a hallmark of obesity, confirmed by the Lee index 300 . The increase in body weight is attributed to the rich caloric diet and fat accumulation in various parts of the body, leading to excessive growth of adipose tissue [26]. The body weight of the obese animals was significantly reduced by MEMf at the dose $50 \mathrm{mg} / \mathrm{kg}$ and Atorvastatin $(10 \mathrm{mg} / \mathrm{kg})$. Similarly, studies carried out by Athesh and Jothi [27] and Kaveripakam et al. [14] revealed a decrease in body and organ weight in HFD-induced obese rats and mice, after administration of Acorus calamus and Stereospermum suaveolens, respectively.

Cholesterol is an important structural component of the cell, in addition, it is the precursor for the synthesis of steroid hormones. Nonetheless, hyperlipidemia occurs when there is an abnormal increase in the total plasma concentrations of TC, TG and LDL-C with a reduction of HDL-C level. Hyperlipidemia forms the basis of the development of coronary heart diseases, which by themselves, constitute a major health problem of great concern [21]. In this study, rats that received only HFD registered a significant increase in serum TC, TG, LDL-C and VLDL-C levels, while HDL-C levels decreased. This may be due to an increase in both de-novo TG and cholesterol synthesis, and intestinal lipid uptake from the fat enriched diet [14]. As the reference drug Atorvastatin, which exhibits similar effects with MEMf in this experiment, has been shown to inhibit 3 hydroxy-3-methylglutaryl-coenzyme A (HMG$\mathrm{CoA}$ ) reductase [6], the normalization of the lipid profile by the plant extract may be due to its ability to lower lipogenesis through inhibition of HMG-CoA reductase. Substances from the plant extract may also enhance lipolysis, suppress appetite and reduce lipid absorption [14]. The observed improvement of the lipid profile corroborates the findings of Kaveripakam et al. [14] who observed that $40 \mathrm{~d}$ administration of Stereospermum suaveolens in HFD rats decreased the serum concentrations of TC, TG, LDL-C and increased HDL-C levels. Similarly, Joshi et al. [28] demonstrated the benefit of a medicinal herb, Cinnamomum verum, through a decrease of total cholesterol, triglycerides, phospholipids, LDL-C, VLDL-C and AI in New Zealand white male rabbits. A number of lipid parameters have been employed in predicting risk of coronary atherosclerosis and cardiovascular diseases. On a general note, recent data have shown that $\mathrm{AI}$ and CRI are more accurate predictors of cardiovascular risk than traditional lipid parameters [29]. Atherogenic dyslipidemia, characterized by a combination of increased TG, LDL-C and AI levels and decreased HDL-C level, was observed in the HFD control animals. This confirms that HFD could predispose to atherosclerosis and consequently to cardiovascular diseases [21]. When the HFD-fed rats were administered MEMf, this resulted into a profound reduction in the atherogenic and coronary risk indices and thereby further supporting the hypolipidemic effect of MEMf.

In animal and human studies, obesity is connected with a decrease in tissue or plasma antioxidant capacity characterized by low levels of antioxidant enzymes predominantly catalase, glutathione peroxidase and glutathione reductase. Antioxidants have been reported to play an important role in the enhancement of antioxidant defence mechanisms in the obese rodent model [30]. Moreover, antioxidants have been shown to be the natural protector against lipid peroxidation. They are important scavengers of superoxide ions and hydrogen peroxide thus preventing hydroxyl radicals generation and protecting cellular constituents from oxidative damage $[17,31]$. HFD has been shown to increase free radical production in vivo, which results in elevated TBARS levels [30]. The altered antioxidant system in HFD-induced obese rats, characterized by reduction of SOD and CAT activities and glutathion levels as well as increased TBARS could be due to the accumulation of superoxide radicals and hydrogen peroxide [30]. Interestingly, this was normalized by MEMf, probably because of its richness in antioxidant molecules such as polyphenols, flavonoids and vitamin C [17]. This is in accordance with the findings of Kim et al. [32] who reported a similar trend with red ginseng alleviating the reduction in SOD activity in HFD-exposed rats. Similarly, Kumar et al. [33] observed a reduction in TBARS levels upon administration of Gymnema sylvestre ethanol extract to HFD-induced obese diabetic rats. The hypolipidemic effect of MEMf could therefore be due to its content in antioxidants, as the reference drug Atorvastatin also exhibits antioxidant activity $[6,17,34,35]$.

Both doses of MEMf all showed interesting pharmacological effects in obese rats. However, the smaller dose of MEMf, $50 \mathrm{mg} / \mathrm{kg}$ seemed to be more effective than $100 \mathrm{mg} / \mathrm{kg}$, precisely on animal body weight, TC, TG, LDL-C and AI. The higher anti-obesity effect at the lower dose of the MEMf showed a certain saturating activity of the active ingredient(s) of $M$. foetida between 50 and $100 \mathrm{mg} / \mathrm{kg}$. Inconsistent dose-response effect was equally reported with the Bauhinia purpurea extract on biomarker such as body weight, lean mass, total free fat and leptin levels in high caloric diet-induced obese male rats [36]. More attention could be laid on the dose 50 $\mathrm{mg} / \mathrm{kg}$ of MEMf in future studies.

\section{CONCLUSION}

The findings from this study support the ability of MEMf to normalize hyperlipidemia, oxidative stress and increased visceral organ weights induced by HFD in rats. Therefore, $M$. foetida is an interesting medicinal plant that could be exploited as a source of anti-obesity agents.

\section{ACKNOWLEDGMENT}

The authors are thankful to Dr Kada Sanda Antoine for his contributions in animal handling and recording of physiological parameters.

\section{FUNDING}

\section{Nil}

\section{AUTHORS CONTRIBUTIONS}

CTA designed the experiment and wrote the manuscript, CHAN carried out the experiments and participated in drafting the manuscript, SD contributed in designing the experiment, MM assisted in experimental investigations and AAD edited the manuscript.

\section{CONFLICT OF INTERESTS}

The authors declare no conflict of interest in the publication of this manuscript.

\section{REFERENCES}

1. WHO. Obesity and overweight; 2020. Available from: https://www.who.int/news-room/fact-sheets/detail/obesityand-overweight. [Last accessed on 21 Feb 2021]

2. OECD. Obesity Update 2017. Available from: https://www.oecd.org/els/health-systems/Obesity-Update2017.pdf. [Last accessed on 21 Feb 2021]

3. q3. NCD-RisC (NCD Risk Factor Collaboration). Trends in adult body-mass index in 200 countries from 1975 to 2014: a pooled analysis of 1698 population-based measurement studies with $19 \cdot 2$ million participants. Lancet 2016;387:1377-96.

4. Nansseu RJ, Noubiap JJ, Bigna JJ. Epidemiology of overweight and obesity in adults living in cameroon: a systematic review and meta-analysis. Obesity (Silver Spring) 2019;27:1682-92.

5. WHO. Obesity and overweight; 2003. Available from: https://www.who.int/dietphysicalactivity/media/en/gsfs_obe sity.pdf. [Last accessed on 21 Feb 2021] 
6. Mohamed AG, Ibrahim MRS, Elkhayat SE, El Dine SR. Natural anti-obesity agents. Bull Fac Pharm Cairo Univ 2014;1:1-16.

7. Pasquet P, Temgoua LS, Melaman Sego F, Froment A, Rikong Adie $\mathrm{H}$. Prevalence of overweight and obesity for urban adults in Cameroon. Ann Hum Biol 2003;30:551-62.

8. Marseglia L, Manti S, D’Angelo G, Nicotera A, Parisi E, Di Rosa G, et al. Oxidative stress in obesity: a critical component in human diseases. Int J Mol Sci 2015;16:378-400.

9. Berke ME, Morden EN. Medical management of obesity. Am Fam Physician 2000;62:419-26.

10. Kavita P, Sanjivani K, Lena B, Gerard EM, Lawrence JC. Nutraceutical supplements for weight loss: a systematic review. Nutr Clin Pract 2011;26:539-52.

11. Kang GJ, Park CY. Anti-obesity drugs: a review about their effects and safety. Diabetes Metab J2012;36:13-25.

12. Albaugh VL, Abumrad NN. Surgical treatment of obesity [version 1;referees: 4 approved] F1000Res 2018;7:617. DOI:10.12688/f1000research.13515.1)

13. Patra S, S Nithya S, B Srinithya B, Meenakshi SM. Review of medicinal plants for anti-obesity activity. Transl Biomed 2015;6:3.

14. Kaveripakam SS, Adikay S, Retnasamy G. Anti-obesity efficacy of roots of Stereospermum suaveolens in high fat-induced obese rats. J Young Pharm 2017;9:234-8.

15. Froelich S, Onegi B, Kakooko A, Siems K, Schubert C, Jenett Siems K. Plants traditionally used against malaria: phytochemical and pharmacological investigation of Momordica foetida. Braz J Pharmacogn 2007;17:1-7.

16. Osinubi AA, Enye LA, Adesiyun AE, Ajayi GO. Comparative effects of three herbs and standard hypoglycaemic agents on blood glucose in normoglycaemic, hyperglycaemic and alloxaninduced diabetic male rats. Am J Emerg Med 2008;7:5-11.

17. Nantia AE, Soh D, Choumessi TA, Ngum NNM, Chi HAN, Kenfack A. In vitro antioxidant property of the methanol extracts of the whole plant and fruit of Momordica foetida (Cucurbitaceae) Pharm Chem J 2018;5:117-25.

18. Stephens DN. Does the lee obesity index measure general obesity? Physiol Behav 1980;25:313-5.

19. Singh KD, Kumar N, Sachan A, Lakhani P, Tutu S, Nath R, et al. Hypolipidaemic effects of Gymnema Sylvestre on high-fat diet induced dyslipidaemiain Wistar rats. J Clin Diagn Res 2017;11:1-5

20. Nantia AE, Kada SA, Manfo TFP, Choumessi TA, Kewir TS, Tashi S, et al. Momordica foetida (Cucurbitaceae). Extract alleviates parastar (insecticide)-induced toxicity on pancreatic and duodenal $\alpha$ amylase activity in male rats. J Chem Health Risks 2019;9:97-105.

21. Nku CO, Ikpi DE, Nna VU, Agiande GU. Altered serum lipid profile in albino Wistar rats following the consumption of Cola nitidarubra (Kola nut). Aust J Basic Appl Sci 2014;8:82-9.
22. Misra HP, Fridovich I. The generation of superoxide radical during the autoxidation of Hemoglobin. J Biol Chem 1972;247:6960-2.

23. Ellman GL. Tissue sulfhydryl groups. Arch Biochem Biophys 1959;82:70-7.

24. Wilbur KM, Bernhein F, Shapiro OW. The thiobarbituric acid reagent as a test for the oxidation of unsaturated fatty acid by various agents. Arch Biochem Biophys 1949;24:305-13.

25. Gornall AG, Bardwill GS, David MM. Determination of serum protein by means of biuret reactions. J Biol Chem 1949;177:751-66.

26. Padmaja KT, Naidu BP, Kumar HNEG, Ganapathy S, Balaji M. Antiobesity activity of Bauhinia purpurea extract: effect on hormones and lipid profile in high calorie diet induced obese rats. Adv Biosci Biotechnol 2014;5:861-73.

27. Athesh K, Jothi G. Pharmacological screening of anti-obesity potential of Acorus calamus linn. in high fat cafeteria diet fed obese rats. Asian J Pharm Clin Res 2017;10:384-90.

28. Joshi CS, Jain KP, Sharma P. Antiatherosclerotic and lipid lowering effects of Cinnamomum verum in the cholesterol-fed rabbit. Int J Curr Pharm Res 2016;9:75-80.

29. Hartog MGL, Feskens EJM, Hollman PCH, Katan MB, Kromhouy D. Dietary antioxidantflavonoids and risk of coronary heart disease: the Zutphenelderly study. Lancet 1993;342:1007-11.

30. Ansari JA, Uma B, Pillai KK, Haque SE. Effect of rosuvastatin on obesity-induced oxidative stress. Indian J Exp Biol 2012;50:216-22.

31. Kale AM, Bindu MS, Khadkikar P. Role of antioxidants and nutrition in oxidative stress: a review. Int J Appl Pharm 2015; 7:1-4

32. Kim MH, Lee EJ, Cheon JM, Nam KJ, Oh TH, Kim KS. Antioxidant and hepatoprotective effects of fermented red ginseng against high fat diet-induced hyperlipidemia in rats. Lab Anim Res 2016;32:217-23.

33. Kumar V, Bhandari U, Tripathi DC, Khanna G. Protective effect of Gymnema Sylvestre ethanol extract on high fat diet-induced obese diabetic wistar rats. Indian J Pharm Sci 2014;76:315-22.

34. Wassmann S, Laufs U, Muller K, Konkol C, Ahlbory K, Baumer $\mathrm{TA}$, et al. Cellular antioxidant effects of atorvastatin in vitro and in vivo. Arterioscler Thromb Vasc Biol 2002;22:300-5.

35. Sezer DE, Sozmen YE, Nart D, Onat T. Effect of atorvastatin therapy on oxidant-antioxidant status and atherosclerotic plaque formation. Vasc Health Risk Manag 2011;7:333-43.

36. Padmaja KT, Naidu BP, Kumar HNEG, Ganapathy S, Balaji M. Antiobesity activity of Bauhinia purpurea extract: Effect on hormones and lipid profile in high calorie diet-induced obese rats. Adv Biosci Biotechnol 2014;5:861-73. 